WellBeing International

WBI Studies Repository

1986

\title{
The Case for the Use of Animals in Medicine
}

Gary F. Merrill

Rutgers University - New Brunswick/Piscataway

Follow this and additional works at: https://www.wellbeingintlstudiesrepository.org/acwp_arte

Part of the Animal Experimentation and Research Commons, Animal Studies Commons, and the Bioethics and Medical Ethics Commons

\section{Recommended Citation}

Merrill, G.F. (1986). The case for the use of animals in medicine. In M.W. Fox \& L.D. Mickley (Eds.),

Advances in animal welfare science 1986/87 (pp. 227-243). Washington, DC: The Humane Society of the United States.

This material is brought to you for free and open access by WellBeing International. It has been accepted for inclusion by an authorized administrator of the WBI Studies Repository. For more information, please contact wbisr-info@wellbeingintl.org.

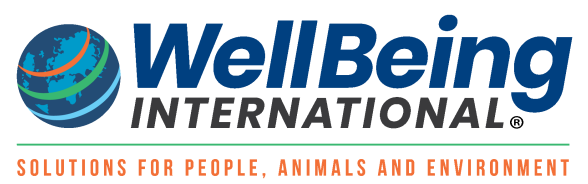




\section{THE CASE FOR THE USE OF ANIIMÁLS IN MEDICINE ${ }^{1}$}

\section{Gary F. Merrill ${ }^{2}$}

\section{Introduction}

As early as $1500-500$ B.C., there are indications of Vedic (Hindu) records of animals being observed by man for medical and scientific purposes. In 300 B.C., in Alexandria, Egypt, Erasistratis placed live birds in closed containers and withheld food to observe the consequences of losing body humors. This is believed to be the first recorded attempt to use live animals for research. The philosopher Aristotle (384-322 B.C.), also a biologist and the son of a physician, founded the sciences of physiology, zoology, and comparative anatomy as a result of his observations of animals. Galen (130-200 A.D.), a physician, anatomist, physiologist, and philosopher, was the founder of experimental physiology. His animal studies were designed to be applicable to humans; their accuracy and completeness greatly improved the understanding of the human body. After the fall of the Roman Empire and during the Dark Ages, the decline that occurred in the arts and sciences was evident in both human and veterinary medicine.The unity that had existed between the two branches of medicine did not reappear until the Renaissance. Thus, the seventeenth and eighteenth centuries saw significant medical advances, many the result of animal studies (Davison 1977).

The use of animals in medical research and teaching, and the public concern this has generated is not a new issue (Visscher 1969). Ever since scientists began using animals to investigate the function of the body in health and disease, there have been those who opposed their work (Fishman and Richards 1982). Whether this controversy is cyclic is not known, but most concerned biomedical investigators agree that the opposition is here to stay. The author shares this opinion, and thus maintains that it is in the best interest of all parties to be properly educated on the issues. Only through the process of education can we accurately evaluate the pros and cons.

The issues to be addressed in this paper entitled "The Case for the Use of Animals in Medicine" include: 1) a selected sample of animals used in biomedical research and teaching and, 2) a selected sample of diseases which have plagued (do plague) man and other animals, and in which animal research has played a major role in minimizing the suffering and early loss of life. The subject is broad and other, more complete, reviews are available (Sechzer 1983). 


\section{Animals Used in Medical Research}

Beginning in June, 1984, the American Physiological Society, one of the many professional biomedical societies dedicated to educating the public and supporting the responsible use of animals in medical research, published a series of articles entitled, "Health Benefits of Animal Research" (Gay 1984). The series, which identifies several animal species currently being used as research subjects in medicine, and the benefits to human health derived from such research, concluded in April, 1985 (King and Yarbrough 1985). These articles are being reproduced as separate chapters in a book entitled, Health Benefits of Animal Research, by the National Association of Biomedical Research, Washington, DC. Much of the information presented in the following section of this paper was taken by permission from this material.

Dog. - The dog has been a companion to man since the dawn of history. As a result of this relationship, both the dog and man have experienced advantages and disadvantages. It is quite logical why this animal was chosen by early biomedical investigators as the species of choice for their scientific experiments. In laboratory surroundings, the dog is smaller and easier to maintain than large agricultural animals. Rats and mice at the time were not thought of in terms of human health and welfare, but rather were disdained as transmitters of disease. Stray dogs were generally abundant then, as now, in urban areas.

The dog's gregarious behavior and highly-developed social nature enhance his manageability in the laboratory. This good nature was recognized and appreciated by earlier medical and behavioral scientists, including Pavlov (1927). Consequently, behavioral genetics has been the subject of considerable research with the dog (Scott and Fuller 1965). Amongst the many clinical diseases for which the dog has been an important research subject are: 1) hereditary spinal muscular atrophy (similar to human motoneuron disease [Cork et al. 1979]); 2) arterial diseases and diseases of the heart, including endocarditis (Keys et al. 1972); 3) hepatitis (Morris and Gocke 1971) and ethanol-induced liver cirrhosis (Chey et al. 1971); 4) neoplastic disease (Dewhirst et al. 1983), including the use of chemotherapy to treat infectious cancer; 5) cholera (Sack and Carpenter 1969); and 6) nutritional disease, including a niacin deficiency syndrome similar to human beriberi (Yang and Mickelson 1974). Perhaps the most well known of all such diseases for which the dog has been used experimentally is diabetes mellitus (see "Diabetes" below).

Rat. - The rat is used experimentally in the fields of immunology, reproduction, cancer, behavior, and aging, amongst others. It is also of universal economic importance since it destroys one-fifth of the world's crops annually and transmits a variety of diseases to humans (Canby and Stanfield 1977). The consequences to man of the rat's destructive activities and its major contributions to human health through biomedical research make the rat one of the most important species with which man must continue to interact.

The strain of rats that has been used most for experimental biomedical research is the Norway rat (Rattus norvegicus), and its early history has been 
described by Robinson (1965). In the middle of the nineteenth century, the rat was used for studies in nutrition, physiology, and anatomy. The research rats used in the United States are thought to have originated in Europe. The first inbred lines of rats were developed independently by several groups of investigators at the beginning of the twentieth century. The first studies were in basic genetics and cancer research.

The rat is a major animal for the biomedical investigation of aging. Inbred and randomly-selected strains show major spontaneously-developing, agerelated diseases of the heart and kidneys, as well as the nervous, endocrine, skeletal, and immune systems (Baker et al. 1979). Rats are susceptible to the development of: 1) spontaneous, 2) virally-induced, and 3) chemicallyinduced tumors in all organ systems (Baker et al. 1979). The rat provides models for both diabetes mellitus and diabetes insipidus. The rat is the best animal model currently available for the study of spontaneous, insulin-dependent (juvenile onset) diabetes in humans (Baker et al. 1979).

Rabbit.-Because the general physiology of cells, sera, tissues, and organs of rabbits exhibit a similarity to that of humans, rabbits have been and will continue to be excellent models for many human diseases. The rabbit is large enough to provide adequate quantities of tissue for experimental work without pooling of samples, but is small enough to be more economical than pigs, monkeys, or dogs. Blood samples can be taken without serious harm to the animal from birth to adulthood in sufficient quantity for performance of routine biochemical tests. Rabbits are an excellent mammalian model system for the investigation of placental transfer of drugs, steroids, and other metabolites due to the fact that the rabbit and human have the same type of placenta (hemochorial), which allows the closest contact between maternal and fetal circulations (Fox et al. 1982; Kozma et al. 1974).

Degenerative diseases occur with increasing age in man and all other species. To study the aging process, the National Institute of Aging suggested the rabbit as a species of potential use (CAMRA 1981). There are a number of changes that have been observed in rabbits with increasing age, including: 1) changes in blood composition, 2) cardiovascular changes, 3) endocrine levels, 4) nerve responses to stimuli, and 5) visual parameters.

The author has recently noted the similarity between the response of coronary arteries to the vasoconstrictor effects of histamine in the rabbit. (Tozzi and Merrill 1985) and those reported in humans (Ginsberg et al. 1981; Toda 1983). Interestingly, in the rabbit, histamine administration can cause ischemic (lack of coronary blood flow) heart disease (Tozzi and Merrill 1985). This disease causes anginal pain in humans and is associated with high mortality in industrialized nations. Thus, the rabbit might prove to be an acceptable animal model in which to study coronary heart disease.

Subbuman Primates. - Primates share more biological and behavioral characteristics with humans than do any other animal species. These interesting similarities begin with the basic chemical component of life, deoxyribonucleic acid (DNA); ninety- eight percent of the molecular composition of human DNA can be found in subhuman primates. 
While anthropologists study subhuman primates for clues to human origins and nature, behavioral scientists examine social organization and interactions in these animals seeking to understand principles governing sexual behavior, aggression, and other social behaviors. In neurobiology, immunology, pathology, reproductive biology, teratology, neonatology, and cardiology, subhuman primates are indispensible biomedical research models for both understanding basic physiological mechanisms and the development of new approaches to the diagnosis and treatment of disease.

Until the 1960s, cardiovascular research was conducted primarily in rabbits, dogs, chickens, rats, and swine. Subhuman primates became major subjects of heart research when it was discovered that atherosclerotic vascular plaques were similar developmentally, microscopically, and biochemically in humans and monkeys (Taylor et al. 1962, 1963a, 1963b). Subhuman primates now are used in cardiovascular research with the following objectives: 1) to identify the mechanisms of atherosclerotic destruction at the organ, cellular, and molecular levels (Ross 1983); 2) to understand the role of diet, blood pressure changes, and other factors in the advancement and stabilization of the disease (Mott et al. 1983); and 3) to define the relative influence of risk factors (tobacco, alcohol, hypertension, obesity, etc.) on disease progression, regression, and prevention (Wissler 1980).

The subhuman primate is also being used in non-cardiovascular disease research. Hepatitis B is a viral disease that annually afflicts 200,000 people in the United States alone. There are approximately 200 million carriers of hepatitis B worldwide. At least three million infants born in Southeast Asia alone will become carriers and develop severe liver damage, including liver cancer (King and Yarbrough 1985). In 1981, the United States Food and Drug Administration approved the world's first hepatitis $\mathrm{B}$ vaccine (Maugh 1981). This major advance depended on research with chimpanzees and other subhuman primates, since hepatitis B cannot be transmitted to other laboratory animals.

Other areas of biomedical research in which subhuman primates are being studied include AIDS and vision research. (The chimpanzee is thus far the only laboratory animal that has proven susceptible to the AIDS infectious agents (McClure et al. 1984; Science News 1984). One of the most recent contributions of primate research to human clinical treatment has been the studies of Wiesel and Hubel (Wiesel 1982). These studies, for which the authors received the Nobel Prize, involved the development and functioning of the visual system in monkeys. Their results underlie the emphasis on early diagnosis and treatment of human infants with visual disorders.

Cats. - Cats made the cover of Time magazine, December 7, 1981 (Reed 1981). They made it for their capacity as people pleasers, their role as the country's most adaptable companion animal, and their potential as a new source of revenue for cartoonists and merchants who have recognized the cat's national popularity. It is estimated that there are 34 million cats inhabiting 24\% of the households in America, and another 15 million who are homeless. In the past 30 years, the health of the house-dwelling cat has improved to 
such a degree that a life expectancy increase of six to eight years allows many felines to reach the age range of 16-20 years. Improvement in the feline's health has been brought about, in great part, by better nutrition, new and improved diagnostic procedures and surgical techniques, and treatment and drug therapies for such conditions as feline urolithiasis, skin disorders, fractures, conjunctivitis, anemia, tumors, and pneumonia, and vaccines for the prevention of many life-threatening diseases such as feline enteritis, thinotracheitis, pneumonitis, and most recently for feline leukemia (Lewis et al. 1981). This improved quality of life for felines could not have been brought about without the aid of biomedical research-research which often relied on the cat as the subject.

Not dealt with in the Time article was the cat's contribution to medical research, perhaps because it is a very unpopular subject with a small segment of the public (Cornelius 1969).

In 1894, Murey, a French physiologist, used the motion-picture camera to illustrate how the cat's body changed position when it was dropped from a height, landing eventually on its feet (McDonald 1960). This observation led physiologists in the early 1900s to examine the physiology of the falling reflex and to come to the conclusion that the brain, and either the eyes or the balancing mechanism (vestibular organs) in the ears, were essential to the cat's landing on its feet. It was not determined, until 1960, that of the two systems, the eyes were more important (Beadle 1977; McDonald 1960).

It is not uncommon for cats that are well cared for to reach the age range of $16-20$ years. Thus, this species is suitable for investigating the aging process. It is of interest that many of the procedures used to study aging do not require surgical intervention, nor do they adversely affect the health and wellbeing of the animal. Studies of the aging process in cats has yielded information of relevance to both man and pets, an important factor in view of the increased interest in the role of companion animals, especially for the older population. Although animals (cats, dogs, birds, fish, reptiles) are being prescribed for their therapeutic value with the mentally retarded, physically handicapped, and prisoners, one of their most valuable contributions is with the aged population; cats are the animal most often used in these settings.

Behavioral scientists use the cat for studies of behavioral development, comparative evaluation, and behavioral assessment. Examples of human conditions studied in the cat include neuroses, amphetamine psychosis, learning and memory, socialization, and habit formation. Of the many diseases cats and humans share, probably one of the best known is leukemia. The causative agent of leukemia in the cat is a ribonucleic acid (RNA) virus belonging to the family Retroviridae, a retrovirus. Of great current medical interest are the reports of retroviruses associated with AIDS in humans (Sarngadharan et al. 1984) and SAIDS (Simian Acquired Immune Deficiency) in animals (Marx et al. 1984).

Mice.-Throughout history, mankind has suffered the ravages of disease. Plagues have decimated large segments of the population. Hundreds of 
millions of people died from the "black plagues" caused by Yersinia pestis, a bacterium transmitted from rodents to humans via fleas, or by infectious droplets from pneumonic victims. In the early 1900s during the influenza virus pandemic, bacterial meningitis and pneumonia associated with Haemopbilus influenza caused countless deaths. As late as 1950, whooping cough caused by Bordetella pertussis killed over 1,000 American children. The threat of bacterial disease is not a thing of the past as evidenced by the recent experience in the United States with Legionnaires' Disease caused by a newly recognized bacterium Legionella pneumophila.

Parasitic diseases are a major cause of human death and suffering. Schistosomiasis, a blood fluke affecting millions of people, is fortunately of limited public health importance in the United States.

The mouse has played a fundamental role as an experimental animal in many of the infectious diseases just discussed. Mice were, and, in many cases still are an essential part of diagnostic medical microbiology. They are important in viral isolation studies of diseases caused by arthropod-borne vectors and in rabies virus diagnosis. Mice are still a significant investigative model for understanding basic host mechanisms of disease, and for studying susceptibility and resistance to infectious agents (Jonas 1984). A basic understanding of host-parasite relationships is critical if we are to achieve better diagnostic, preventive medical approaches, and therapeutic applications to these problems.

In addition, there is a long list of diseases of humans that are usually thought to be non-infectious but cause immense suffering and in many cases contribute to mortality. Arthritis, diabetes mellitus, central nervous system disorders, immune deficiency diseases, metabolic disorders, hematologic dyscrasias, and cancer are diseases that are all too familiar. The use of mice has provided us with a valuable method to elucidate fundamental biological phenomena associated with these diseases. Through creative basic and applied research studies, we have developed effective therapeutic measures for infectious and noninfectious diseases.

Abnormalities of development are frequently associated with genetic dysfunction. Down's syndrome is a tragic example of a chromosome disorder resulting in a child with a "mongoloid" appearance, mental retardation, cardiac abnormalities, and an increased likelihood of developing leukemia. Through plant and animal investigations, we have gained an understanding of genetic disease that has enabled us to diagnose and, in some cases, treat genetic disorders. Genetic counseling of prospective parents is now commonplace. The use of mice in studying basic genetics at the classical and molecular levels has resulted in development of organ transplantation as well as effective methods to modify the course of immunologic disease. With advances in molecular biology it is now possible to think in terms of modifying genetic errors of metabolism by gene manipulation.

The history of microbiology is intimately interwoven with experimental studies using mice. Pasteur used mice in studying both rabies and anthrax. Mice were at the forefront of experiments dealing with the nature of infectious disease and immunization. The mouse has been and will continue to be an 
excellent research animal to study the pathogenesis of bacterial diseases. For example, a model for human antimicrobialassociated diarrhea (AAD) was developed using Clostridium difficile as a causative organism. This work used the mouse as the experimental animal (Onderkonk et al. 1980).

Developmental analysis of an animal model of a human disease makes it possible to determine what happens metabolically before the actual disease symptoms appear. Not only does this understanding of a disease's progress help design therapy but also allows early detection and treatment. Because so many genes have been mapped in the mouse (Pearson et al. 1982), it is usually possible to identify the presence of a disease-causing gene early by "tagging" it with a closely linked marker gene. One example of this is the diabetes gene (Coleman 1978), which is closely linked to a coat color gene in the mouse called misty $(m)$ (Wooley 1943, 1945). By making appropriate matings, it was possible to link the diabetes gene $(d b)$ with the $m$ gene. Thus it is possible to follow the development of diabetes from shortly after birth by simply analyzing those mice with the misty coat color. Analysis of the $d b$ gene in mice has led to a better understanding of the complex nature of hormonal abnormalities on cellular metabolism.

Mice are also being used to study the structure of immunoglobulins, diseases of the blood-forming elements such as aplastic anemia or leukemia, and in the development of blood assay systems, e.g., there are at least 17 different mutations in the mouse that cause anemias (Russell 1979).

\section{Medical Advances Made Through Animal Research}

Diabetes. - The term diabetes mellitus comprises a heterogeneous group of disorders characterized by high blood glucose levels. Approximately 5.8 million people in the United States have been diagnosed by a physician as being diabetic, and an additional four to five million people have diabetes but have not yet been diagnosed (approximately 500,000 new cases are diagnosed annually). There are four main types of diabetes. Insulin-dependent diabetes mellitus (IDDM) constitutes about $510 \%$ of all cases of diabetes, and most of the remainder is noninsulin-dependent diabetes mellitus (NIDDM). About $2 \%$ of diabetes is the type that is secondary to or associated with other conditions. Gestational diabetes, a transient condition occuring in about $2-5 \%$ of pregnancies, is one such malady.

The annual incidence of IDDM is about 12-14 new cases per 100,000 children ages $0-16$ years, and by age 20 , about $0.3 \%$ of persons have developed IDDM. About one-half of the persons with IDDM are currently older than age 20 years. The annual incidence of NIDDM is about 320 per 100,000 persons ages 20 years or older. About $2.35 \%$ of the population has been diagnosed as having NIDDM, and at ages 65 years and older, virtually $8.6 \%$ have NIDDM.

Diagnosis of diabetes is made either by the presence of the classical symptoms of diabetes accompanied by elevated blood glucose levels, by elevated fasting glucose levels, or by an abnormal oral glucose tolerance test. 
In $1982,34,583$ deaths were attributed to diabetes as the underlying cause of death, resulting in diabetes being ranked as the seventh leading underlying cause of death. In approximately 95,000 additional deaths, diabetes was listed as a contributing cause of death. The majority of death certificates (about 75\%) listing diabetes also list a cardiovascular condition. Ischemic heart diseases are involved in about $60 \%$ of diabetes deaths, and cerebrovascular diseases in about $25 \%$.

Diabetes is not a benign disease. It causes almost $50 \%$ of amputations of the foot and leg among adults. It causes about $20 \%$ of all cases of kidney failure and $15 \%$ of all blindness. Diabetes in the mother causes about $3 \%$ of all stillbirths and neonatal and perinatal deaths. The United States ranks among the highest five nations in the world in mortality due to diabetes.

It is of interest that the first major preclinical breakthrough in diabetesrelated research was achieved in dogs (Best 1974). It had been shown by a variety of investigators that complete removal of the pancreas always resulted in fatal diabetes. Dogs were the experimental animal. Therefore, it was inevitable that Fred Banting and Charles Best would choose the dog as the experimental animal for their studies which lead to the ultimate discovery in insulin (Best 1974). Both Banting, an expert surgeon, and Best, a medical school student studying experimental physiology, had personal interest in diabetes. Dr. Banting had watched a child in Alliston, Ontario, lose weight and eventually develop diabetic coma and die. An aunt of Charles Best developed diabetes in 1912. The only known therapy at the time was the under-nutrition regimen (Allen et al. 1982). Best's aunt followed the diet faithfully, but died of diabetic coma in 1918 (Best 1984).

When these investigators were provided with research facilities in the Department of Physiology, University of Toronto, in 1921 to study the disease, they were told that only ten dogs would be provided for their proposed studies. The cost per animal in those days was approximately one dollar. When the ten dogs had been used, and suitable results were still lacking, Banting and Best purchased additional dogs with their own funds. In those days, they had no stipends or grants to support their research. In final studies (August and September, 1921), they performed scores of experiments providing convincing evidence that the secretory extracts of beef pancreas (they and others had hypothesized that presence of an anti-diabetic factor) could reverse the symptoms seen in diabetic (pancreatectomized) dogs.

Because of personal interest in the outcome of their experiments, they looked after the dogs themselves; fed them and cleaned their cages. They trained the dogs to put out their paws for withdrawal of blood samples and they made the dogs as comfortable as possible under the circumstances. In the words of Charles Best, "I do not think that in these or subsequent experiments we ever inflicted pain and discomfort on dogs which we would not have been willing to accept ourselves" (Best 1974). The animals that were pancreatectomized before insulin was available and which lived for ten days to two weeks, were necessary as controls for the animals that received insulin. 
Banting and Best presented the results of their research before the Physiological Society in Toronto in November, 1921, and before the American Physiological Society in December, 1921. On January 10, 1922, they gave each other injections of their purified insulin (Best 1974). There were no untoward effects except a mild soreness of their arms. On the following day, the material was taken to Toronto General Hospital where a 14-yearold boy, Leonard Thompson, became the first diabetic to receive insulin. The first patient to receive insulin in the United States was James Havens of Rochester, New York. He became a celebrated artist and lived to help raise a fine family.

The travels of Banting and Best in some 70 different countries brought them in contact with thousands of diabetics. Statisticians have told them that figures based on worldwide consumption of insulin indicate that some 130 million diabetics have had their lives prolonged by insulin (Best 1974). Today, of course, the number is even greater.

Fred Banting and Charles Best had two great hopes in 1921 and 1922. The first hope was that the dramatic recovery of diabetic animals could be consistently produced by insulin in human patients. The second was that insulin would become an important agent in metabolic research. Both hopes have been realized. As evidenced by the fact that volumes have been written on these two subjects, it is safe to say that perhaps no other physiological agent has been so instrumental in revealing so much about the intermediary metabolism of carbohydrates, fats, and proteins, as has insulin.

Childbood Communicable Diseases and Vaccines. - A report of "teething paralysis" by Colmer (1843) is thought to be the first description of an outbreak of paralytic poliomyelitis in the United States. For many years, poliomyelitis was primarily manifested as an endemic disease, occurring sporadically among infants and young children, but in the early years of this century, epidemics began to appear, and so-called "infantile paralysis" was soon reported in older children and adults (Paul 1971).

During the 1940s, there was a marked increase in the incidence of poliomyelitis in the United States. For example, between 1920 and 1940, there was an annual incidence of about five cases per 100,000 population. By 1945, the incidence had risen to approximately $15-20$ cases per 100,000 , and by the early 1950 s, it had escalated to an estimated $40-45$ cases per 100,000 population (Salk 1980). Similar increases were observed in other developed countries at the time, while developing countries noted an increased incidence and shift from an endemic to epidemic pattern (Paul 1958).

The conquest of polio began in 1909, when Landsteiner and Popper (1909) demonstrated that poliomyelitis could be transmitted from humans to apes and monkeys. Subhuman primates became a key animal model for studies on the pathogenesis of polio and for vaccine development when it was recognized that among animal species, only monkeys and chimpanzees could contract human poliomyelitis.

After a decade of intense, focused research employing mice, cats, chick embryos, and subhuman primates (Jonas Salk, personal communication), a killed poliovirus vaccine (KPV, sometimes referred to as inactivated poliovirus 
vaccine) was introduced into general use in the United States in 1955. This followed a large-scale, controlled field trial in 1954 (Francis et al. 1955), in which the author, and numerous other American children became the first recipients of the protective effects of the polio vaccine. Between 1955 and 1962 ,there was a sharp decline in the incidence of poliomyelitis in the United States, decreasing to fewer than five cases per 100,000 population; a decrement of approximately $95 \%$.

The impact of the polio vaccine on human health, developed totally through the use of animal experimentation, has been nothing less than dramatic. In the peak years of the polio epidemic in the United States, there were an estimated 50,000-60,000 cases reported per year. Many victims died or were left permanently crippled. In the immediate years following a federally-subsidized campaign to vaccinate all American children, there were fewer than ten cases per year (Salk 1980).

Similar results, based on research in animals, have had impacts on other communicable childhood diseases. In 1934, before final development and routine administration of the pertussis ("whooping cough") vaccine, more than 265,000 cases were reported in the United States. More than 7,500 victims died. In 1982, there were fewer than 2,000 reported cases with about four deaths.

In 1980, the World Health Organization announced the worldwide elimination of smallpox. Hence, the development of vaccines against communicable diseases, resulting from animal research, has provided society-wide health benefits. Today, all 50 states require routine vaccination of children against smallpox as a condition for entering school.

Interestingly, the protection against such epidemics cannot be extended to subpopulations who refuse vaccination. Fox et al. (1971) described an outbreak of smallpox in a well-immunized community in eastern Nigeria that was confined entirely to members of a small religious sect who refused vaccination. This group was dispersed throughout the community, but maintained close social ties and relative segregation from the rest of the population.

The 1978 and 1979 outbreaks of poliomyelitis in The Netherlands, Canada, and the United States are strikingly similar to the above example. Since 1961, outbreaks of poliomyelitis in The Netherlands have occurred only in certain Protestant communities with very low vaccine acceptance rates. Between April 15 and October 12, 1978, a total of 110 cases of poliomyelitis (80 paralytic, 30 non-paralytic) occurred in several different Dutch provinces amongst members of a Protestant religious denomination that refuses vaccination. The majority of the cases (99) occurred among 65,000 unvaccinated individuals under 27 years of age (Bijkerk 1979). This outbreak was geographically widespread, but no cases of poliomyelitis occurred among 435,000 unvaccinated individuals under age 27 who were not members of these religious denominations. Also in 1978, several cases of poliomyelitis were reported among members of a religious group in Canada. This latter group is related to the group involved in The Netherlands outbreak (Furesz 1979). 
There had been contact between the Canadian group and visitors from The Netherlands prior to the outbreak.

In 1979, poliomyelitis appeared in the largely unvaccinated Amish population of the United States, which includes approximately 75,000 members (CDC 1979). The first paralytic case occurred in January in a Pennsylvania town to which a Canadian fanily had recently moved from a town in Ontario near an area affected with poliomyelitis in 1978. There are extensive interactions among members of different Amish communities, including contact between groups in the United States and Canada. By mid-spring, it was apparent that wild polio virus type 1 was circulating widely within these communities. The virus was shown to be similar to that circulating in Canada and The Netherlands. By June, 1978, when vaccination campaigns appeared to have controlled the outbreak, a total of 15 paralytic and two non-paralytic cases had been reported.

Cardiovascular Disease. - The story of the diagnosis, treatment, and prevention of cardiovascular disease is the story of animal research. It begins in antiquity with the discovery of the structure and function of the heart, vasculature, blood, and lungs (Fishman and Richards 1982). Of prominence in this story is the discovery by William Harvey (1578-1657) of the circulation of the blood, a feat based on years of observation and experimentation in animals. By an extraordinary chance, the notes of his Lumleiam lecture of April 17, 1616, found their way into the British Museum, where they were discovered in 1886, some 270 years later. Excerpts from these notes, written originally in Latin and English are worth quoting (Franklin 1933):

It is plain from the structure of the heart that the blood is passed continuously through the lungs to the aorta as by two clacks of water bellows to raise water. It is shown by application of a ligature that the passage of blood is from the arteries into the veins. Whence it follows that the movement of the blood is constantly in a circle, and is brought about by the beat of the heart. It is a question, therefore, whether this is for the sake of nourishment or of heat, the blood cooled by warming the limbs, being in turn warmed by the heart.

Bear in mind that his predecessors were convinced that the heart was the source of body heat production and expelled a mixture of blood and air, but not in a circular fashion (Sarton 1954). Harvey continued such experiments throughout his life although it is not always easy to determine just what these experiments were and when he did them. An elegant experiment in the perfusion of the pulmonary circulation is described in a letter written late in his life to his friend Paul Marguat Slegel of Hamburg (Harvey 1766).

... the pulmonary artery and aorta are ligated, the left ventricle opened, and a cannula placed in the vena cava, and water forced in. Quid fit? [What happens?] The right ventricle is vehemently tumefied. Through the opening in the left ventricle, however, not a drop of water or blood escapes... So now (the solution having been predicted), the syringe is introduced into the pulmonary artery, with a ligature around it lest water regurgitate into the right ventricle. 
We force the water in the syringe against the lungs and immediately water with copious amounts of blood leaps out of the cleft in the left ventricle, so that as much water as is expressed into the lungs, so much flows out of the hiatus mentioned. You can experiment as often as you like, and know for certain that this is so.

These and similar experiments designed to prove that blood flows in a circular fashion, i.e., from right ventricle to lungs, thence through the left ventricle to the systemic circulation, and back to the right ventricle, are detailed in Harvey's classic book, Exercitatio anatomica de motu cordis et sanguinis in animalibus, (Guilielmi Harvei, Angli, Francofurti, sumptibus Guilielmi Fitzeri, anno M. DC. XXVIII [Harvey 1928]). This great work in experimental physiology stands by itself. In the medical sciences, there is nothing else in the same class. Its seventeen brief chapters, in 72 pages, are an inexhaustible source of enlightenment and incontrovertible conclusions. Its achievement was more than a discovery: it was a revolution (Fishman and Richards 1982).

Animals, like humans, suffer from many inherited cardiovascular defects, including patent ductus arteriosus, pulmonary stenosis, persistent right aortic arch, intraseptal defect, and both tricuspid and mitral valve insufficiencies. All of the preceding maladies are seen in the dog. Vascular disease, common in the aging dog, is treated clinically in many veterinary practices with drugs and other methods of therapy developed during the last couple of decades for use in humans.

Replacement of heart valves and segments of larger arteries are major cardiovascular advances resulting almost entirely from dog surgery 30 years ago. Hemophilia in the dog is an inherited hemostatic defect considered neariy identical to that seen in himains; it is more frequently reported in dogs than in most other domestic animals (Gay 1984).

One in every two deaths of Americans today can be attributed to cardiovas cular and related disease. The incidence of such diseases, which steadily increased in the post-World War II years, has been on the decline for the past couple of decades. This is due in large measure to the promotion of accelerated activity in biomedical research by the federal government, the biomedical scientific community, and private enterprise. With such promotion has come advanced technology that allows us to intervene in the advancement of cardiovascular disease with new surgical and pharmacological insight that was thought impossible 20 years ago. For example, the early loss of life due to ischemic heart disease (secondary to organic vessel disease, i.e., atherosclerosis) has been greatly reduced with the development of coronary bypass surgery. It should be of little surprise that before such technology was applied to human medicine, it was first thoroughly investigated in experimental animals. Large agricultural species such as sheep, hogs, and cattle, and smaller domestic species such as dogs, were routinely investigated to determine the feasibility of such surgical/pharmacological intervention in man. Few of us are not familiar with persons whose life expectancy has 
been prolonged as the result of coronary bypass surgery. Valve replacement surgery is another intervention routinely performed in man which was first tested and perfected, as far as was possible, in experimental animals.

In November, 1983, the author attended the annual meeting of the American Heart Association held in Anaheim, California. This meeting occurred less than one year after surgeons at the University of Utah Medical Center replaced the first human heart with an artificial counterpart. Drs. William C. DeVries (heart surgeon) and Robert K. Jarvik (heart designer) were both in attendance, as was the wife of Dr. Barney Clark, the first human recipient of a transplanted artificial heart. Dr. DeVries was the keynote speaker. He outlined in considerable detail the years of animal experimentation at the University of Utah and elsewhere which preceded this first human experiment. Dr. DeVries described the experience as follows (DeVries et al. 1983):

\begin{abstract}
Advances in bio-engineering and animal experimentation have led to the possibility of total artificial heart (TAH) implantation in humans. The Utah TAH consists of two spherical ventricles fabricated of polyurethane which are pneumatically powered by an external driver. The TAH use tilting-disk valves. A 61-year-old man presented with end-stage heart failure due to idiopathic cardiomyopathy which was refractory to drug therapy. With informed consent, the TAH was successfully implanted and allowed survival for 112 days. After implantation, increases occurred in blood pressure, from $85 / 70$ to $124 / 60 \mathrm{~mm}$ $\mathrm{Hg}$, left ventricular ejection fraction, from $10 \%$ to $77 \%$, and cardiac output, from 1.5 to $7 \mathrm{l} / \mathrm{min}$. The patient awakened after three hours and was fully alert. He later could be ambulated and exercised with assistance. The postoperative period was complicated by pulmonary insufficiency, intermittent renal failure, seizures (? overperfusion), bleeding complications of anticoagulation, and pseudomembranous colitis with terminal shock. Except for an early valve failure which was corrected, the TAH was functional throughout the cinical course and was intact at autopsy. This initial experience indicates the feasibility of long-term cardiovascular support with a TAH systems, and suggests promise for further development.
\end{abstract}

At the conclusion of his keynote address, Dr. DeVries described the experience as "inspiring" for all who participated. Other such artificial heart transplants have occurred subsequently and will undoubtedly continue to occur at an accelerated rate as technology improves.

\title{
Summary and Conclusions
}

Francois Magendie, a French physiologist of the early nineteenth century, and considered by many to be the father of experimental physiology, was succeeded at the College of France by his former assistant, Claude Bernard. Bernard was a brilliant physiologist who was described by Pasteur as physiology itself. Every phase of physiology to which Bernard addressed himself was explored with innumerable experiments. Bernard did not lack sensitivity towards the animals he used, nor to the views of his anti-vivisectionist opponents. Yet he was undaunted in his belief that his work was justified 
by the potential benefits derived for humanity. In his book, An Introduction to the Study of Experimental Medicine (Bernard 1957), he asks the question:

Have we the right to make experiments on animals and vivisect them?...I think we have this right, wholly and absolutely. It would be strange indeed if we recognized man's right to make use of animals in every walk of life, for domestic service, for food, and then forbade him to make use of them for his own instruction in one of the sciences most useful to humanity. No hesitation is possible; the science of life can be established only through experiment, and we can save living beings from death only after sacrificing others. Experiments must be made either on man or on animals. Now I think that physicians already make too many dangerous experiments on man, before carefully studying them on animals. I do not admit that it is moral to try more or less dangerous or active remedies on patients in hospitals, without first experimenting with them on dogs; for I shall prove, further on, that results obtained on animals may all be conclusive for man when we know how to experiment properly.

The author reaffirms the beliefs held by Claude Bernard. If our motivation for using animals in experimental investigation is to improve the welfare of humanity (and other forms of animal life), then by all means it is not only our right but perhaps our obligation to continue such work.

At a time when the use of animals in experimental research is being seriously debated, it is important to step back and review what has been learned and what may lay ahead in the field of biomedical research and medicine. Scientists as well as the lay public are bound by ethical and moral principles to treat living creatures with respect and to protect their environment. By the manner in which we address relevant biological questions, so shall we be judged by our peers and the public. By the manner in which we manage our environment, so will we be judged by future generations. In the final analysis, it is the function of society to determine whether the gain from animal research with its attendant benefit to man and the environment is justified (Jonas 1984).

The use of animals in experimental research is by its very nature an encroachment on those precepts respecting animal life (Jonas 1984). Nonetheless, man is given by divine decree, "... dominion over the fish of the sea, and over the fowl of the air, and over every living thing that moveth upon the earth" (Genesis 1:28). Therefore, it is incumbent not only on scientists who use animals in medical research, but on every person who uses animals for any purpose to do so with care, compassion, and consideration for the animal's well-being.

\section{Endnotes}

${ }^{1}$ Paper presented at the national conference, "Animals and Humans: Ethical Perspectives," Moorhead State University, Moorhead, MN, April 21-23, 1986.

2 Associate Professor, Graduate Program in Physiology, Bartlett Hall, Cook College, Rutgers University, New Brunswick, NJ 08903. 


\section{References}

Allen, FA 1982. In: Bliss, M. The Discovery of Insulin. Chicago: Univ. of Chicago Press, pp. 105-28.

Baker, HJ, Lindsey, JR and Weisbroth, SH. eds. 1979. The Laboratory Rat. Vols. 1 and 2. New York: Academic Press.

Beadle, M. 1977. The Cat. New York: Simon and Schuster. Chapt. 13. pp. 166-82.

Bernard, C. 1957. An Introduction to the Study of Experimental Medicine. New York: Dover Publications. p. 102.

Best, CH. 1974. A short essay on the importance of dogs in medical research. The Pbysiologist. 17: $437-39$

Bijkerk, H. 1979. Poliomyelitis epidemic in The Netherlands, 1978. Div. Biol. Stand. 43: 195-206.

CAMRA. (Committee on Animal Models for Research in Aging). 1981. Mammalian Models for Research on Aging. Washington, DC: Natl. Acad. Sci. p. 587.

Canby, TY and Stanfield, JL. 1977. The rat-lapdog of the devil. Natl. Geo. 15: 60-87.

CDC. (Center for Disease Control). 1979. Poliomyelitis. Morbid. and Mort. Wkly. Rep. 28: 49-50, 229-30, 309, 34546.

Chey, WY, Kosay, S, Siplet, H and Lorber, SH. 1971. Observations on hepatic histology and function in alcoholic dogs. Am. J. Dig. Dis. 16: 835-38.

Coleman, DL. 1978. Obese and diabetes: Two mutant genes causing diabetes-obesity syndromes in mice. Diabetologist. 14: 141-48.

Colmer, G. 1843. Paralysis in teething children. Am. J. Med. Sci. 5: 248-50.

Cork, LC, Munnell, JF, Lorenz, MD, Adams, RJ, Griffin, JW and Price, DL. 1979. Hereditary canine spinal muscular atrophy. J. Neuropathol. Exp. Neurol. 38: 209-21.

Cornelius, CE. 1969. Animal models - - a neglected medical resource. N. Eng. J. Med. 281: 934-44.

Davison, FC. 1977. Historical perspectives of biomedical experimentation. In: The Future of Animals, Cells, Models, and Systems in Research, Development, Education and Testing. Washington, DC: Natl. Acad. Sci. pp. 7-15.

Dewhirst, MW, Sim, DA, Wilson, S, DeYoung, D and Parsells, LJ. 1983. Correlation between initial and long-term responses of spontaneous pet animal tumors to heat and radiation or radiation alone. Cancer Res. 43: 5735-41.

DeVries, WC, Joyce, LD, Anderson, FL, Anderson, Ju, Jarvik, RK and Kolff, WJ. 1983. Initial human application of the Utah total artificial heart. Circul. 68: III-89, October

Fishman, AP and Richards, DW. 1982. Circulation of the Blood: Men and Ideas. American Physiological Society:Baltimore, Maryland, Waverly Press.

Gay, WI. 1984. Health benefits of animal research. The dog as a research subject. Pbysiol. 27(3) $133-41$.

Fox, JP, Elveback, L, Scott, W, Gatewood, L and Ackerman,E. 1971. Herd immunity: Basic concept and relevance to public health immunization practices. Am. J. Epidemiol. 94: 17989

Fox, RR, Muir, H, Bedigan, HG and Crary, DD. 1982. Genetics of transplacentally induced teratogenic and carcinogenic effects in rabbits treated with $\mathrm{N}$-nitroso- $\mathrm{N}$-ethylurea. J. Natl. Can. Inst. 69: 1411-17.

Francis, T, Jr., Korn, RF, Voight, RB, Boisen, M and Tolchinsky, E. 1955. An evaluation of the 1954 poliomyelitis vaccine trials: Summary report. Am. J. Pub. Health. 45: 1-63.

Franklin, KJ. 1933. A Short History of Plyysiology. London: Bale.

Furesz, J. 1979. Poliomyelitis outbreaks in The Netherlands and Canada. Can. Med. Assoc. J. 120: 905-6.

Ginsburg, R, Bristow, MR, Kantrowitz, DS and Harrison, DC. 1981. Histamine provocation of clinical coronary artery spasm: Implications concerning pathogenesis of variant angina $\mathrm{Am}$ Heart J. 102: 819-22.

Franklin, KJ. 1933. A Short Fistory of Physiology. London: Bale 
Furesz, J. 1979. Poliomyelitis outbreaks in The Netherlands and Canada. Can. Med. Assoc. J. 120: 905-6.

Ginsburg, R, Bristow, MR, Kantrowitz, DS and Harrison, DC. 1981. Histamine provocation of clinical coronary artery spasm: Implications concerning pathogenesis of variant angina $A m$ Heart J. 102: 819-22.

Harvey, W. 1766. Epistola prima Paulo Marquarto Slegelio,Hamburgensis, April 7, 1651. In his Opera Omnia. London: Letters collected by Bowyer. p. 613.

- 1928. Exercitatio anatomica de motu cordis et sanguinis in animalibus. With an English translation by CD Leake. Springfield, IL: Thomas. First edition, 1628.

Jonas, Àí. 1984. The mouse in Diomedical research. The Physiologist. 27(5): 330-46.

Keys, TF, Sapico, FL, Touchon, R, Barenfus, M and Hewitt,WL. 1972. Experimental interococcal endocarditis. Description of a canine model. Am. J. Med. Sci. 63:103-9.

King, FA and Yarbrough, CJ. 1985. Health benefits of animal research. Medical and behavioral benefits from primate research. Physiol. 28(2): 75-87.

Kozma, C, Macklin, W, Cummins, LM and Mauer, R. 1974. Anatony, physiology and biochemistry of the rabbit. In: The Biology of the Laboratory Rabbit. Weisbroth, SH, Flatt, RE and Kraus, AL. eds. New York: Academic Press. pp. 49-72.

Landsteiner, $\mathrm{K}$ and Popper, E. 1909. Ubertragung der poliomyelitis acuta auf affen. $A$ Immunitaestforsch. 2: 377-90.

Lewis, MG, Mathes, LE and Olsen, RG. 1981. Protection against feline leukemia by vaccination with a subunit vaccine. Infect. Immun. 34: 888-94.

Marx, PA, Maul, DH, Osborne, KG, Moody, P and Gardner, MB. 1984. Simian AIDS: Isolation of a type D retrovirus and transmission of the disease. Science. 223: 1083-86.

Maugh, TH, III. 1981. FDA approves hepatitis B vaccine. Science. 214: 1113-17.

McClure, HM, Swenson, B, King, F, Chermann, JC, Sinousi, J and Macher, A. 1984. Experimental infection of chimpanzees with lymphadenopathy associated virus. Morb. Mortal. Wkly. Rep. 33: 442-43

McDonald, D. 1960. How does a cat fall on its feet? New Scientist. 7: 1649-57.

Morris, TQ and Gocke, DJ. 1971. Modified acute canine viral hepatitis-a model for physiologic study Proc Sor Exp. Biol. 139: 32-36.

Mott, GE, McMahan, CA, Kelly, J, Mersinger-Farley, C and MCGill, H, Jr. 1983. Influence of infant and juvenile diets on serum cholesterol, lipoprotein cholosterol, and lipoprotein concentration in juvenile baboons. Atberosclerosis. 45: 191-201.

Onderdonk, A, Cisneros, $\mathrm{R}$ and Bartlett, J. 1980. Clostridium difficile in gnotobiotic mice. Infect. Intmunol. 28: 277-82.

Paul, JR. 1958. Endemic and epidemic trends of poliomyelitis in Central and South America. Bull. WHO. 19: 747-58.

-. 1971. A History of Poliomyelitis. New Haven: Yale University Press. p. 486.

Pavlov, IP. 1927. Conditional Reflexes and Investigations of Physiological Activity of the Cerebral Cortex. Trans. by GU Anrep. New York: Dove.

Pearson, PL, et al. 1982. Report of the committee on comparative mapping. Cytogenet. Cell Genet. 32: 208-20.

Reed, JD. 1981. Crazy over cats. Time. Dec.: 72-79.

Robinson, R. 1965. Genetics of the Norway rat. New York: Permagon Press.

Ross, R. 1983. Recent progress in understanding atherosclerosis. J. Am. Geriat. Soc. 31: 231-35.

Russell, ES. 1979. Hereditary anemias of the mouse: A review for geneticists. Adv. Genet. 20: $357-459$.

Sack, RB and Carpenter, CG. 1969. Experimental canine cholera. Development of a model. $J$. Infect. Dis. 119: 138-49. 
Salk, D. 1980. Eradication of poliomyelitis in the United States. I. Live virus vaccine-associated and wild poliovirus disease. Rev. Inf. Dis. 2: 228-42.

Sarngadharan, MG, Popovic, L, Bruch, J, Schupbach, J and Gallo, RC. 1984. Antibodies reactive with human T-cell lymphotropic retroviruses (HTIV-III) in the serum of patients with AIDS. Science. 224: 506-8.

Sarton, G. 1954. Galen of Permagon. Lawrence,KS: Univ. of Kansas Press.

Science News. 1984. First chimps infected with AIDS virus. 126: 121.

Scott, JP and Fuller, JL. 1965. Genetics and the Social Bebavior of the Dog. Chicago: Univ. of Chicago Press.

Sechzer, JA. 1983. The role of animals in biomedical research. Annals of the New York Acad. of Sciences. Vol. 46.

Taylor, CB, Cox, GE, Morale-Estrella, P and Southworth, J. 1962. Atherosclerosis in rhesus monkeys. II. Arterial lesions associated with hypercholesterolemia induced by dietary fat and cholesterol. Arch. Pathol. 74: 16-34.

Taylor, CB, Patton, DE and Cox, GE. 1963a. Atherosclerosis in rhesus monkeys. IV. Fatal myocardial infarction in a monkey fed fat and cholesterol. Arch. Pathol. 76: 404-12.

Taylor, CB, Manalo-Estrella, P and Cox, GE. 1963b. Atherosclerosis in rhesus monkeys. V. Marked diet-induced hypercholesterolemia with xanthomatosis and severe atherosclerosis. Arch. Pathol. 76: 239-49.

Toda, N. 1983. Isolated human coronary arteries in response to vasoconstricior substances. Am. J. Pbysiol. (Heart Circ. Physiol.). 14: H937-H941.

Tozzi, CA and Merrill, GF. 1985. Evidence of histamineinduced myocardial ischemia: Reversal by chlorpheniramine and potentiation by atherosclerosis. Cardiovas. Res. 19: 74453.

Visscher, MB. 1969. A half century in science and sociery. Am. Rev. Physiol. 31: 108.

Wiesel, TN. 1982. Postnatal development of the visual cortex and the influences of environment. Nature (London). 299: 583-91.

Wissler, RW. 1980. Perspectives on cardiovascular research in primates. In: Kalter, SS. ed. The Use of Nonbuman Primates in Cardionascular Diseases. Austin, TX:Univ. of 'Texas Press. pp. 15-32.

Wooley, GW 1913. "Misty," a new coat color dilution in the mouse Mus musculis. Gonetics. 28 : 95-96.

-. 1945. Misty dilution in the mouse. $f$. Hered. 36: 269-70.

Yang, MG and Mickelson, O. 1974. Laboratory animals in nutrition research. In: Gay, WI. ed. Methods of Animal Experimentation. Vol. 5. New York: Academic Press. pp. 136. 